\title{
From time zero to infinity: transitional and long-run dynamics in capital-resource economies
}

\author{
LUCAS BRETSCHGER \\ CER-ETH Centre of Economic Research at ETH Zurich, ZUE F7, CH-8092 \\ Zurich, Switzerland. Tel: +41 4463221 92, Fax: +41 446321362 \\ Email: lbretschger@ethz.ch
}

\author{
KAREN PITTEL \\ CER-ETH Centre of Economic Research at ETH Zurich, ZUE F12, CH-8092 \\ Zurich, Switzerland. Tel:+41 4463206 12. Fax: +41 446320387 \\ Email: kpittel@ethz.ch
}

\begin{abstract}
It is now generally agreed that the prediction of long-run development has to include natural resource use. To focus on the long run is, however, not equivalent to the use of balanced growth assumptions. It should be kept in mind that reaching a long-run equilibrium might take considerable time. Transition phases often exhibit characteristics which differ from the long-run state of the economy, but are important for its nature.

We discuss a number of different drivers that govern the transition to the steady state, including the development of stocks, substitution possibilities, savings decisions, and institutions. Based on this theoretical evaluation, we discuss five contributions of the conference on sustainable resource use and economic dynamics (SURED 2006) included in this special issue.
\end{abstract}

\section{Introduction}

Recent reports on the world's fading energy supplies and on the climate problem have reawakened the general interest in long-run forecasts. An increasing number of energy and climate studies cover time spans of one or two centuries ahead. In the public debate, global pollution, decreasing fossil fuel supply, and population growth are mentioned prominently as reasons for a pessimistic outlook in the Malthusian tradition. Conversely, appropriate environmental policies, efficient resource markets, substitution mechanisms, and increasing knowledge about efficient resource use give rise to more optimistic predictions. From the seminal contributions in resource economics in the 1970s (see Solow, 1974; Stiglitz, 1974; Dasgupta and Heal, 1974, 1979), input substitution and technical progress emerged as crucial to determine the future of welfare in capital-resource economies. In addition, Hartwick (1977) showed that the investment share is crucial for whether or not the decline in natural resource inputs can be compensated. In the wave of new growth theory, the determinants of endogenous 
innovations have become the focal point of explanations (see, for example, Bovenberg and Smulders, 1995; Scholz and Ziemes, 1999; Smulders, 2000; Groth and Schou, 2002; Grimaud and Rougé, 2003; and Xepapadeas, 2005).

Looking far into the future also has an impact on the methodology that is used. In growth theory, for a long time the focus was almost exclusively on development in terms of balanced growth. But this is not always an adequate procedure, especially not for capital-resource economies. Nonrenewable resources, stock pollution, environmental policies, and structural change can easily produce a non-linear development during the transition to the balanced growth path (BGP), which may take substantial time. A prominent example is the discussion on the Environmental Kuznets Curve, which suggests long-term non-monotonic behaviour of the economy. Interestingly, in López et al. (2007) structural change is identified as a major topic in the sustainability debate. The characteristics of the convergence path can have a major impact on the nature of the long-run steady state. Thus, the forecasts for the far future are often better understood when analysing the transition period.

In this paper, we discuss the relevance of the balanced-growth path assumption and compare it to the importance of the transition toward the long-run path. Specifically, we focus on the forces driving transitional and BGP dynamics, including the motion of different stocks as the duration of convergence processes depends crucially on their convergence speed. In addition, we argue that the elasticity of substitution between inputs has a major impact on the transition path. This holds especially true for capitalresource economies when the aggregate production function is of the more general CES type and not simply Cobb-Douglas. In this case, changing resource quantities affect the accumulation of all other stocks. A similar effect is observed in the case of adjustment costs. Furthermore, we consider the impact that the savings decision of the households, as well as policy measures and the quality of institutions, have on the adjustment path and on the BGP. How complex the interrelations between the different drivers of the transition can get is finally shown for the example of the relationship between income and the environment. Based on this theoretical evaluation, we discuss five contributions of the conference on sustainable resource use and economic dynamics (SURED 2006) included in this special issue.

The remainder of the paper is organized as follows: section 2 introduces key elements of the capital-resource economy and takes a first look at the characteristics of its short- and long-dynamics. The forces driving these dynamics are investigated in more detail in section 3. Section 4 brings together theory and empirics of transition processes, exemplified for the case of Environmental Kuznets Curves. Section 5 concludes.

\section{A general approach}

\subsection{Basic modelling elements}

Consider a capital-resource economy with inputs (public) knowledge $A$, capital $K$, resources $R$, and population $L$, where total output $Y$ is determined 
by

$$
Y(t)=A(t) F[K(t), R(t), L(t)]
$$

with $t$ denoting the time index. $F$ is often considered to be a linearly homogeneous function as in, for example

$$
Y(t)=A(t)^{\eta} K(t)^{\alpha} L(t)^{\beta} R(t)^{\gamma} \quad \eta, \alpha, \beta, \gamma>0, \alpha+\beta+\gamma=1 .
$$

A wide range of contributions using this type of Cobb-Douglas specification can be found in the literature. Results derived within this framework encompass, for example, the role of population growth, and returns to capital, as well as the scale effect of growth (e.g. Groth, 2007).

Current income depends on resource use $R$, which is, in the case of non-renewable resources, directly connected to the finite resource stock $S$ according to

$$
\dot{S}(t)=-R(t) \equiv-u(t) S(t) .
$$

For renewable resources, (3) is modified to

$$
\dot{S}(t)=-R(t)+G(S, t),
$$

where $G$ represents a natural regeneration function. In (1)-(4), the environment is considered as a source of rival environmental services, that is resource inputs to production. The environment as a (public) sink for pollution can be analysed in a similar way. Stock pollution exhibits similarities to renewable or even non-renewable resource use. The latter applies, for example, to substances or - more generally - to negative effects of human activities on nature that cannot be absorbed by the environment. Flow pollution such as noise on the other hand can be incorporated in the above system by assuming instantaneous regeneration.

Simple capital-resource models rely on a production structure in which consumer and all types of investment goods are produced with equal input intensities according to (2). This type of model, which we refer to as a one-sector structure, has been labeled 'lab equipment model' by RiveraBatiz and Romer (1991). Approaches that are more elaborate use a separate production sector for the accumulation of $A$, emphasizing that knowledge emerges under different conditions compared to consumer and capital goods (see also section 3.1).

In addition to (3) or (4), respectively, economic development is governed by the dynamics of the man-made capital stocks ( $A$ and $K$ ) and the development of population $(L)$ over time. The respective equations of motions of these stocks complement the model. Closing the production side of the model system finally requires considering factor market equilibria.

In most capital-resource models, the household side of the economy is quite standard: representative consumers maximize lifetime utility subject to an intertemporal budget constraint. They supply labour and receive income in the form of wages, resource rents, and interest on capital. In addition, it can be assumed that household utility also depends on environment-related variables such as pollution, environmental quality, or 
resource stocks (for an overview of the literature, see Pittel, 2002). For simplicity, we abstract from these types of external amenities and damages.

\subsection{Short- and long-run dynamics}

In the standard growth literature, the type of equilibrium usually studied is the balanced-growth equilibrium, which is characterized by constant growth rates. The implicit assumption is that either the economy is already on the balanced growth path, or, if it is not on this path, the economy will head toward it within a limited time period. Along a balanced growth path, for the capital-resource economy given by (2) and (3) and identical production technologies for consumption and investment goods we obtain

$$
g_{Y}=g_{K}=g_{C}=g_{c}+g_{L} ; g_{R}=-u,
$$

where $C$ is aggregate consumption, while $c=C / L$ denotes per capita consumption. Following (5), the capital intensity of the economy $K / Y$ is constant in the balanced-growth equilibrium. The growth rates of the capital stock, income, and output per worker might be positive or negative. The growth of resource inputs is negative because the stock is finite.

Balanced growth is a useful concept because in many cases it enables us to find interesting results. Moreover, the empirics of the Western economies in the second half of the twentieth century showed certain regularities, which seem to be compatible with balanced growth. What is often neglected is the transition period through which the economy passes on its way to the steady state. Consequently, relatively little is known about the development of growth and welfare during convergence.

Transitional dynamics are of great importance for two main reasons. First, resource use is expected to decrease in the future and it may take a long period of time until a new equilibrium is reached (see, for example, Dasgupta and Heal, 1974; Bretschger and Smulders, 2006). Second, and even more important, the characteristics of the transition path might determine the long-run state of the economy. This path dependency has been found in various contexts and may also be a key to understanding natural resource use. To illustrate this point, consider technical progress as expressed by an increase in $A$ in (2). The implicit resource-augmenting nature of this technical progress is needed for an optimistic outlook on longrun development. However, it may well be that the history of knowledge accumulation during the transition determines the types and levels of research done in the long run. Of course, the causality between the short and long run can also be reversed, that is the nature of the BGP might have feedback effects on the transition.

\section{Drivers of transitional dynamics}

\subsection{Motion of the stocks}

For the duration and shape of the transition path, accumulation (or possibly decumulation) processes with respect to the different stocks constitute fundamental drivers. As long as the growth rate of any stock is not constant, the economy is not on a BGP. The interrelation between the different stocks can enforce the non-linear behaviour of the economy. 
Let us consider the different stocks, $A, K, S$, and $L$, successively by taking a look at the standard assumptions made about their dynamics, and the impacts these assumptions have on capital-resource economies.

\section{Resource stock}

The motion of the resource stock is given by (3) and (4). The growth rate of the stock is negative if the resource is exhaustible. Sustainable use of renewable resources is generally associated with a constant or increasing resource stock. Besides the stock, resource prices as well as substitution possibilities matter for the quantity of resource extraction.

The Hotelling rule predicts that resource rents increase with the interest rate - given that a number of simplifying assumptions hold (see Hotelling, 1931). Institutional failures such as incomplete property rights (see section 3.5) may, for example, induce deviations from the Hotelling path.

The demand for resources depends on substitution possibilities (see also section 3.2). Potential substitutes can range from other types of natural (exhaustible or renewable) resources to man-made (physical or knowledge) capital and labour. Yet, most of these potential substitutes are equally limited in supply. Substitution by natural resources is either restricted by the substitute's stock, as in the case of exhaustible resources, or by the speed of regeneration, as with respect to renewable resources. A more favourable outlook on long-run development could be obtained by the introduction of a backstop technology, that is a technology that fully substitutes for the natural resource at constant marginal costs. For energy purposes this could, for example, be solar energy or nuclear fusion. Currently, however, technological development has not succeeded in providing such an energy source.

\section{Physical capital}

Regarding the accumulation of physical capital, the usual assumption is that the production of capital and consumer goods employs the same production technology and input intensities. In the neoclassical tradition, physical capital, $K$, consequently evolves according to

$$
\dot{K}(t)=Y(t)-C(t)-\delta_{K} K(t), \quad \delta_{K} \geq 0,
$$

where $\delta_{K}$ is the depreciation rate of physical capital.

Estimations of the rate at which the capital stock converges towards its steady state predict a convergence speed not higher than $2 \%$ per year (see Mankiw et al., 1992). The resulting adjustment period therefore covers several decades or more, which shows the importance of transitional dynamics.

Let us now reconsider physical capital as a potential substitute for natural resources. The question arises whether the scope for substituting resource inputs with physical capital might be limited as well. First, as the generation of physical capital requires the input of resources, the accumulation of $K$ is itself bounded. Second, even if no material limits to the physical capital stock existed, inspection of (2) and (5) shows that the accumulation of capital alone cannot ensure long-run per capita growth in the presence of decreasing returns to capital. Expressing (2) in growth rates, consideration 
of $g_{Y}=g_{K}$ along the BGP and $g_{A}=0$ gives

$$
g_{\frac{Y}{L}}=\frac{\gamma}{1-\alpha}\left(g_{R}-g_{L}\right)
$$

Assuming as before that resources are exhaustible, that is $g_{R}<0$, this implies in the long run negative per capita growth in the absence of technological progress.

Third, it has often been argued that production requires a minimum resource input, which suggests that a Cobb-Douglas technology (2) is technically not feasible - a discussion that has been at the core of the weak versus strong sustainability debate for years.

As neither natural resources nor physical capital seem to represent viable options for long-run growth, the only remaining option (abstracting from backstop resources for the moment) is to continuously increase their efficiency, that is long-run growth requires technological progress that increases the stock of knowledge.

\section{Knowledge capital}

Regarding the dynamics of the knowledge stock, several hypotheses have been employed in the literature. Earlier resource economics assumed it to be exogenous and derived the rate of technical progress necessary to compensate for the resource drag (see, for example, Nordhaus, 1992). The assumption of exogenous technological progress is, however, quite unsatisfying as no interaction arises between resource scarcity and the rate as well as the direction of technological change.

The accumulation and production of knowledge can be endogenized by assuming that the technology for creating new knowledge uses the same inputs as manufacturing in the same proportions. $A$ then increases through R\&D investment $I_{A}$, and the dynamics of $A$ are given by

$$
\dot{A}(t)=I_{A}(t)-\delta_{A} A(t), \quad \delta_{A} \geq 0,
$$

where $\delta_{A}$ is the depreciation rate for knowledge. The dynamics of the physical capital stock modify accordingly to

$$
\dot{K}(t)=Y(t)-C(t)-I_{A}(t)-\delta_{K} K(t) .
$$

Although an economy in which knowledge is produced according to (8) comprises an additional production process for $A$, it is usually still referred to as a one-sector structure as only one technology is employed in the production of consumption and capital goods. Knowledge investment is in this case treated like capital investment in the neoclassical tradition. Compared to exogenous technological progress, this formulation retains the advantage of analytical simplicity, but also constitutes an endogenous link between resource extraction and investment in knowledge. The drawback is, however, that investment in knowledge capital is perfectly correlated with the investment in physical capital in the long run (that is $g_{A}=g_{K}$ along the BGP). Shocks to resource prices or productivity affect all sectors equally.

Departing, however, from the simplifying assumption of identical technologies, it can be assumed that knowledge is produced by one/several 
specific sectors employing differing production techniques. In a capitalresource economy, this has far-reaching consequences as the price increase of natural resources relative to other input factors makes research more attractive relative to consumer goods production and investment in physical capital (see Bretschger, 1998, 2005).

With respect to the direction of research, different assumptions can be made. Technological progress can, for example, be resource- and/or capital-augmenting. Still, if manufacturing is modelled according to (2), a specific characterization as resource- or capital-augmenting has no impact, as technological progress is always augmenting all factors. If, however, the substitution elasticity between inputs is smaller than unity, steady state growth requires resource-augmenting technological progress. To account for this, models sometimes simply assume technological progress to be resource-augmenting, an assumption that has regularly attracted criticism.

An option to avoid this critique is to endogenize the direction of research by introducing different types of $R \& D$, where investors are free to allocate their means to different types of research (see Acemoglu, 2003, and, in a capital-resource economy, Di Maria and Valente, this issue). This set-up not only allows decoupling knowledge and capital investment, but also accounts for specific directions of technological change. These models help to answer the questions of how much should be invested in R\&D, and how this investment in R\&D should be allocated between sectors.

Di Maria and Valente assume that final output is produced from resource- and capital-intensive intermediates using a CES-type production technology

$$
Y=\left[v \tilde{K}^{\frac{\sigma-1}{\sigma}}+(1-v) \tilde{R}^{\frac{\sigma-1}{\sigma}}\right]^{\frac{\sigma}{\sigma-1}}
$$

where $\tilde{K}$ and $\tilde{R}$ are capital-intensive and resource-intensive goods that are each assembled from $i$ differentiated intermediate products, $y_{i}^{K}, i \in(0, m]$ and $y_{i}^{R}, i \in(0, n] . \sigma$ denotes the elasticity of substitution between $\tilde{K}$ and $\tilde{R}$, which - in contrast to (2) - is assumed to be less than unity (for the effects of this type of technology specification see also section 3.2). $v \in(0,1)$ is a weighing parameter.

Intermediates are either produced from resources $\left(y_{i}^{R}\right)$ or capital $\left(y_{i}^{K}\right)$ employing one-to-one production technologies. Combining the individual intermediates to $\tilde{K}$ and $\tilde{R}$ gives rise to gains from specialization, such that

$$
\tilde{K}=\left(\int_{0}^{m} K_{i}^{\beta} d i\right)^{\frac{1}{\beta}} \text { and } \tilde{R}=\left(\int_{0}^{n} R_{i}^{\beta} d i\right)^{\frac{1}{\beta}}
$$

hold. $\beta \in(0,1)$ captures the positive effect from diversification on productivity. The efficiency of the capital-intensive and resource-intensive good can be increased by developing new types of intermediates by sectorspecific research.

In the Di Maria and Valente paper, the direction of technological change is endogenous and driven by the relative profitability of innovations in capital- and resource-intensive intermediate sectors. In the steady state, 
technological progress is purely resource-augmenting, while research is conducted in both sectors during the transition. In the long run, capitalaugmenting research is completely crowded out by the necessity to offset increasing resource prices by increasing resource efficiency. The authors not only show that the direction of research depends crucially on whether transitional dynamics or the steady state are considered, but also that purely resource-augmenting technological change is a result of a sound microfoundation rather than an assumption.

\section{Population}

The potential of technological progress to overcome resource-related limits to growth depends on population dynamics. If population grows faster than resource efficiency, even a constant output per capita requires everincreasing resource inputs.

Population growth is often assumed to be exogenous and exponential. In the wave of new growth theory, it has been reduced to zero in many models because constant returns in innovation combined with a growing population produce ever-increasing growth rates (see Romer, 1990). In the semi-endogenous growth literature, it is again positive and even determines the long-run growth rate (see Jones, 1995). Non-exponential but possibly richer formulations of population growth like quasi-arithmetic population growth (see Asheim et al., 2007) have rarely been considered.

Regardless of the specific dynamics of exogenous population growth, the exogeneity assumption per se prevents an interaction between other economic variables and fertility decisions. This transmission channel is only open to approaches that consider endogenous population growth, postulating, for example, that population growth declines with increasing living standards (see Tamura, 2000; de la Croix and Doepke, 2003).

Although demographic transition processes are well documented by empirical research and deeply affect the prospects of capital-resource economies being sustainable, they have so far rarely been considered in the related literature.

\subsection{Input substitution}

One major impact on the characteristics of the transition process comes from input substitution. Take the widely employed Cobb-Douglas specification of equation (2). The associated unitary elasticity of input substitution has its merits as it simplifies calculations considerably and resources are essential inputs. The unitary elasticity is, however, a serious restriction. For example, sector-specific investment in resource-augmenting technological change is not required, as technological progress is allocation-neutral under this specification (recall section 3.1). When the elasticity of input substitution is not exactly equal to unity, economic development takes quite a different direction, so that the Cobb-Douglas specification is in fact a knife-edge assumption.

Most empirical studies find elasticities of substitution between inputs to be smaller than unity (see, for example, Christopoulos and Tsionas, 2002; Kemfert, 1998). With poor input substitution, it is not feasible to have 
positive long-run growth in a one-sector model as represented by

$$
Y(t)=\left[\eta A(t)^{\frac{\sigma-1}{\sigma}}+\alpha K(t)^{\frac{\sigma-1}{\sigma}}+\beta L(t)^{\frac{\sigma-1}{\sigma}}+\gamma R(t)^{\frac{\sigma-1}{\sigma}}\right]^{\frac{\sigma}{\sigma-1}} .
$$

Given the production technology (12), man-made capital accumulation and population growth cannot compensate for the decline of exhaustible resources in the long run (see Dasgupta and Heal, 1974; Groth, 2007). Even if $A, K$, and $L$ are increasing over time, output goes to zero for $R \rightarrow 0$ as

$$
\lim _{R \rightarrow 0}\left(\frac{Y(t)}{R(t)}\right) \cdot R(t)=\gamma^{\frac{\sigma}{\sigma-1}} \cdot 0
$$

This restriction could be overcome, for example, by introducing sectorspecific technological knowledge, $A_{K}, A_{L}$, and $A_{R}$, where investment in $A_{i}$ enhances the productivity of the respective sector $i$. Assuming sectorspecific research activities additionally provides the possibility of intersectoral substitution (see, for example, Bretschger, 1998), thereby allowing for directed technological change (see Bretschger and Smulders, 2006; Di Maria and Valente, this issue). The analytics of such a model are obviously much more complex than in a simple Cobb-Douglas one-sector economy. The resulting dynamics and economic intuition are, however, richer.

CES and Cobb-Douglas specifications have to be carefully distinguished in the following case, which is often applied in capital-resource models. Following Romer (1990) and Grossman and Helpman (1991), aggregate output is assembled from differentiated intermediate goods varieties $x_{i}$, $i \in[0, A]$, according to a CES production technology

$$
Y(t)=\left(\int_{0}^{A} x_{i}(t)^{\beta} d i\right)^{\frac{1}{\beta}}, \quad 0<\beta<1 .
$$

Assuming for analytical convenience that production technologies for the $x_{i} \mathrm{~s}$ are identical gives

$$
Y(t)=A(t)^{\frac{1}{\beta}} x(t)
$$

in equilibrium. Equation (15) exhibits the same convenient properties as the Cobb-Douglas specification in (2). A, however, is not a regular input in (14) but represents the 'number' of differentiated intermediates. It is assumed that producing a specific type of intermediate requires a patent for the corresponding blueprint, generated by an upfront investment in research and financed by the present value of profits from selling the respective intermediate. As each intermediate can only be produced by one firm - the patent-holder $-A$ also gives the 'number' of intermediate firms. Moreover, its dynamics reflect the dynamics of knowledge capital, as $A$ is usually taken to approximate the stock of (public) knowledge. Rewriting (15) in terms of aggregate intermediates production $X(t)$

$$
Y(t)=A(t)^{\frac{1-\beta}{\beta}} X(t)
$$


shows that $A$ is also a productivity index for the total input of intermediates $X$ in $Y$-production. $(1-\beta) / \beta$ gives the gains from diversification that determine the impact of knowledge accumulation and innovation on production.

Although (15) resembles (2), it only emerges due to the symmetry assumption regarding $x_{i}$ production. Nevertheless, the CES specification (14) is clearly distinct from a Cobb-Douglas function. In comparison with an aggregated specification of production and research as given in (1) and (8), the microfoundation upon which this model builds also gives rise to a different steady state as well as transitional dynamics.

In capital-resource economies, intermediates are often produced from labour, natural resources, and physical capital, where $X=X(L, R, K)$ can be assumed to be of the CES type. Abstracting from population growth for the moment and taking logarithmic differentials of (16) exhibits that growth again has to be driven by $A$, that is by an increasing variety of intermediates. In order to have economic growth, these gains from diversification have to be so strong as to overcompensate the resource drag operating through a decrease of $X$ over time.

\subsection{Adjustment costs}

Growth theory often assumes that physical capital stocks are completely immobile between sectors, while labour can be reallocated without any costs. The effects of adjustment costs on steady states and on transitional dynamics are not regarded. Landon (1990) shows that, in the presence of adjustment costs, the speed of adjustment decreases. The fact that adjustment costs also affect the steady state is shown by Steger (2007). He finds that positive productivity shocks translate into a smaller increase in BGP growth if factor reallocation costs are higher.

Adjustment costs are usually considered either in the form of capital installation costs or factor reallocation costs.

The former can already be studied in a relatively simple one-sector structure. Assume, for example, that gross investment only partially translates into installed capital (see Hayashi, 1982), that is

$$
\dot{K}(t)=h(Y(t)-C(t))-\delta_{K} K(t),
$$

where $h(\cdot)$ denotes an increasing and concave installation function.

The latter, however, require multi-sector models that allow us to analyze the reallocation of input factors across sectors. In a capitalresource economy, this type of adjustment cost is of special importance, as resource scarcity induces intrasectoral as well as intersectoral structural change. Due to the increase in resource prices, it becomes profitable, for example, to reallocate labour from resource-intensive production towards resource-augmenting research (intersectoral change), or simply within the research sector from capital- to resource-augmenting research (intrasectoral change).

To exemplify intersectoral change, consider an economy in which two sectors, one conducting research and one producing output, employ labour $\left(L_{A}\right.$ and $\left.L_{Y}\right)$. The trade-off between the input of labour in either sector can 
be shown using an effective labour possibility frontier (ELPF)

$$
L_{Y}(t)=h\left(L_{A}(t)\right),
$$

where the ELPF is the locus of efficient allocations of labour (in efficiency units) between the two sectors. Given the standard assumptions that labour is fully mobile and homogeneous and that wages are completely flexible implies that the ELPF is linear.

However, as soon as the assumption of a perfect labour market is dropped, the transition phase to the long-run equilibrium has a very different shape, as shown in Amigues et al. (this issue). The authors assume that individuals differ in their ability to work in manufacturing or research. This leads to a trade-off that leaves the ELPF concave rather than linear. Thus, Amigues et al. consider an ELPF of the following form

$$
h\left(L_{A}(t)\right)=L_{Y}^{\max }\left[1-\left(\frac{L_{A}}{L_{A}^{\max }}\right)^{\rho}\right], \quad \rho>1,
$$

for their simulations, where $L_{A} \in\left(0, L_{A}^{\max }\right)$ and $L_{Y}^{\max }=h(0)$.

Under the assumed heterogeneity of labour, opportunity costs of research in terms of output increase with the level of research activity. It is shown that the shape of the ELPF matters with respect to the transition to the steady state, although steady state levels are not affected. In the long run, flexibility plays no role, as the allocation of labour is constant. In the short run, however, flexibility matters as labour shares are adjusted along the transition path. The higher the flexibility of the work force, that is the less concave the ELPF, the more research is conducted during the transition and the faster the adjustment to the steady state.

\subsection{Savings decisions}

So far we have exclusively focused on production-related drivers of transition processes. Nevertheless, households' savings decisions also play an important role not only for the prospect of an economy being sustainable in the long run, but also for the shape of the transition path and the speed of convergence.

A first link between savings and sustainability is provided by Hartwick (1977), who stipulates that sustainability in the sense of constant consumption requires that rents from resource extraction be completely reinvested in man-made capital. Assuming (2) with technology and population constant, this means that the savings rate has to equal a specific value.

When assuming utility-maximizing agents as in the Ramsey model, savings decisions become endogenous but are generally not compatible with the Hartwick rule. In this case, sustainability requires technological progress in order to follow a sustainable path. These types of models give richer transitional dynamics, as the rate of convergence depends on households' discount rates as well as their intertemporal elasticity of substitution. Comparative statics exercises show that the exploitation of natural resources may depend negatively on households' patience, as 
higher patience increases investment in the environment. However, there is a counteracting effect if investment in physical capital induces pollution.

In the context of capital-resource economies, the endogeneity of savings rates becomes of particular interest when it is considered that households' willingness to save, that is their discount rate, might depend directly upon the state of the environment as represented, for example, by the stock of natural capital or the amount of pollution (see Pittel, 2002).

Other aspects of household behaviour that determine the dynamics of development are altruism and bequests. Yet, as intertemporal capitalresource models are to a large extent set in continuous time (as also assumed in section 2), both are regularly ignored in the literature. Their explicit consideration, however, might help to explain different economic adjustment patterns following changes in resource scarcity as well as changes in policies (see Frederiksen, this issue).

Frederiksen analyzes how altruism in combination with resource abundance and public spending policies affect growth and welfare within an overlapping generations framework. She considers an economy in which resource revenues $E(t)$ can be spent on lump-sum transfers $T(t)$ and investment in public services $G(t)$. The balanced budget constraint of the government reads

$$
T(t)+G(t)=E(t) .
$$

Resource rents are assumed to equal a constant share of output, $E_{t}=$ $\varphi Y(t)$. Lump-sum transfers, $T(t)=\tau E(t)$, are split between the young and the old. Resource revenues not used for transfers are invested in public services, $G(t)=(1-\tau) E(t)$, which have a positive effect on output production

$$
y(t)=\operatorname{Mg}(t)^{\alpha} k(t)^{1-\alpha}, \quad 0<\alpha<1,
$$

where $y(t), k(t)$ and $g(t)$ denote output, capital, and public services per capita, respectively, and $M$ is a constant productivity parameter.

The author shows that policy effects depend on whether the economy is in a bequest or no-bequest growth regime. It is assumed that individuals maximize the present value of utility, $U(t)$, over the two periods of their life

$$
U(t)=u\left(c_{1 t}\right)+\rho u\left(c_{2 t+1}\right)+\omega U(t+1),
$$

where $u\left(c_{1 t}\right)$ and $u\left(c_{2 t+1}\right)$ denote instantaneous utility from consumption when young and old and $\rho$ is the discount factor. Parents are concerned about the welfare of their offspring, $U(t+1)$, where $\omega$ characterizes their degree of altruism. Bequests are made if altruism is sufficiently high.

If bequests are absent, a decline in growth due to higher resource revenues may arise (resource curse). In this case, the share of lump-sum transfers to the old induces a negative effect on saving when young that results in a decline in growth. Given that bequests are made, however, a resource curse situation can never arise. The result that policy outcomes depend on growth regimes helps to explain why identical spending policies might generate different effects in different countries. 


\subsection{Policies and institutions}

The development of economies is not solely determined by the pure market forces of demand and supply. The outcome of economic processes is to a large extent also governed by public authorities via the design of economic institutions and policies. Both the quality of the institutions as well as the nature of policies determine how an economy fares with respect to its short- and long-run development. Empirical analyses show, for example, that equally resource-rich countries may face very different development perspectives, a finding which some authors attribute mainly to differences in institutions (see Mehlum et al., 2006).

Among different types of economic institutions, property rights have probably received the most attention in the context of resource economics. Open access resources, externalities, and uncertainty about future ownership are just some of the keywords that underline the importance of well-defined property rights for the growth prospects of economies.

The effects of different property regimes on the equilibrium yield and stock of a renewable resource are at the center of Halsema and Withagen (this issue). They analyse the case of two lakes in regions 1 and 2, in which homogeneous fish $R(t)$ are caught. Under the assumption of logistic regeneration, the general formulation of the dynamics of renewable resource stocks in (4) are specified as

$$
\dot{S}_{i}(t)=r S(t)\left(1-\frac{S_{i}(t)}{S_{i}^{\max }}\right)-R_{i}(t), \quad i=1,2
$$

where $S_{i}^{\max }$ is the carrying capacity of the lakes in regions 1 and 2 and $r$ denotes the intrinsic growth rate of the stocks. The authors analyse the different market outcomes under open access versus private ownership (price taking and monopolistic firms), assuming either autarky or a common market. Their analysis shows that the consequences of introducing a common market can be substantial and differ depending on the types of property regimes in the two regions. They also consider the effect of ecosystem size on the equilibrium. Larger carrying capacities always imply higher equilibrium stocks, whereas the catch does not necessarily rise.

Let us now turn from the analysis of institutions and property rights to environmental and resource policies. Inspection of the literature reveals that policy analysis focusses to a large extent on long-run effects. It is often ignored that policies represent shocks to a system that induce transitorial adjustment which may take a considerable amount of time. In this light, findings like those of Steger (2007) - although made in a no-resource economy - about short- as well as long-run policy effects in the presence of reallocation costs should be reconsidered. He shows that shocks which positively affect long-run growth might in the short run induce a downturn of economic activity. Moreover, factor reallocation costs might induce differences in the long-run effects of policies - the higher the adjustment costs, the lower the gain. 


\section{From theory to evidence}

The previous section showed that the growth-theoretical analysis of transition processes incorporates a number of different determinants between which a multitude of interrelations exist. It is these interrelations that make the analysis of the determinants important and difficult at the same time. In the environmental and resource economics literature, this is well reflected by the discussion on the development of the income-pollution relation, $Y / P$, over time. It is generally agreed that a number of different forces are at work that might give rise to non-monotonic time paths. The causal complexity of this analysis can be exemplified along the lines of the previously examined determinants of transition:

(a) Savings decisions of households: It is claimed that households' preferences for a clean environment increase with income, leading to changes in their consumption and saving patterns.

(b) Motion of the stocks: Due to higher preferences for the environment as well as rising resource prices, investment behaviour as well as production technologies adjust such that the development of the stocks changes.

(c) Input substitution and adjustment costs: Cleaner consumer preferences induce input substitution, which might be facilitated by technological progress. Reallocation of factors entails costs that slow down adjustment and thereby affect the shape and turning point of an EKC.

(d) Policies and institutions: First, it is argued that increasing household preferences for the environment boost environmental regulation. Second, empirical studies have shown that income is positively correlated with the quality of institutions.

Due to their manifold interactions, the respective contributions of (a) to (d) to the development of the income-pollution relation are hard to delineate - empirically as well as theoretically. As a consequence, papers that concentrate on the theoretical underpinnings of the income-pollution relation have mostly dealt with potential drivers in a one-by-one fashion (see, for example, Smulders et al., 2005; Egli and Steger, 2007).

In empirical analysis, the complexity of the income-pollution relationship is best reflected by the discussion on the Environmental Kuznets Curve (EKC). Following empirical observations, it has been argued that there is an inverted u-shaped relationship between some types of pollution and per capita income (for an overview of the related literature, see Dasgupta et al., 2002; Stern, 2004). Uncertainty about the causality behind the $Y / P$ development is reflected in this literature by controversies on regressor identification, data selection, and adequate estimation techniques. Begun and Eicher (this issue) argue that 'in light of such model uncertainty, inference procedures based on a single regression analysis overstate the precision of coefficient estimates'. They introduce Bayesian Model Averaging (BMA) to the EKC analysis to deal with this uncertainty about possible theories and regressors. BMA considers this uncertainty by taking different models into account and weighing them by 
their relative quality. It thus generates a probability that a specific regressor is related to the dependent variable.

Begun and Eicher employ this approach with data on $\mathrm{SO}_{2}$ concentrations. As stressed by Lieb (2004: 484), 'almost all studies agree that there is an EKC for sulphur dioxide'. The authors, however, find only weak support for an $\mathrm{SO}_{2}$-EKC, which even disappears when, for example, oversampling of data is addressed.

\section{Conclusions}

It is undisputed that natural resources, specifically their input to production, as well as the repercussions of their use on the environment are crucial for the long-run development of economies. The literature on economic growth and resource scarcity mirrors this, as its focus is mainly on the very long run, that is on balanced growth paths. Although the long-run perspective is important, this should not distract from the fact that reaching a steady state might take considerable time. Adjustment processes may not only exhibit characteristics that are substantially different from the BGP, but can also be crucial for the nature of this BGP. Neglecting these adjustment processes could consequently have strong implications for short- as well as longterm welfare. This paper argues for the consideration and analysis of these adjustment processes.

We have discussed a number of different drivers that govern the transition to the steady state, including the development of stocks, substitution possibilities, savings decisions, and policies/institutions. The contributions to this special issue consider some of these drivers (Amigues et al., Di Maria and Valente, Frederiksen). They aim at increasing our understanding of adjustment processes, as well as the importance of the underlying economic and institutional structures (Halsema and Withagen).

To do justice to sustainability we need short- and long-term predictions, which should be as reliable as possible. As the interrelations between the different forces driving the environment-resource-economy nexus are complex, this task requires tools that allow us to differentiate between alternative theories. The last contribution to this special issue (Begun and Eicher) introduces a method to accomplish this task.

The research presented in this issue underlines the importance of adjustment processes and long-run dynamics in the context of capitalresource economies and will hopefully encourage future work along these lines.

\section{References}

Acemoglu, D. (2003), 'Labour- and capital-augmenting technical change', Journal of the European Economic Association 1: 1-37.

Asheim, G. B., W. Buchholz, J. M. Hartwick, T. Mitra, and C. Withagen (2007), 'Constant savings rates and quasi-arithmetic population growth under exhaustible resource constraints', Journal of Environmental Economics and Management 53: 213229.

Bovenberg, A. L. and S. A. Smulders (1995), 'Environmental quality and pollutionaugmenting technical change in a two-sector endogenous growth model', Journal of Public Economics 57: 369-391. 
Bretschger, L. (1998), 'How to substitute in order to sustain: knowledge driven growth under environmental restrictions', Environment and Development Economics 3: $425-442$.

Bretschger, L. (2005), 'Economics of technological change and the natural environment: how effective are innovations as a remedy for resource scarcity?', Ecological Economics 54: 148-163.

Bretschger, L. and J. A. Smulders (2006), 'Sustainability and substitution of exhaustible natural resources: how resource prices affect long-term R\&Dinvestments', Economics Working Paper Series 03/26, ETH Zurich.

Christopoulos, D. and E. Tsionas (2002), 'Allocation inefficiency and the capitalenergy controversy', Energy Economics 24: 305-318.

Dasgupta, P. S. and G. Heal (1974), 'The optimal depletion of exhaustible resources', Review of Economic Studies 41, Symposium on the Economics of Exhaustible Resources, 3-28.

Dasgupta, P. S. and G. Heal (1979), Economic Theory and Exhaustible Resources, Cambridge: Cambridge University Press.

Dasgupta, S., B. Laplante, H. Wang, and D. Wheeler (2002), 'Confronting the Environmental Kuznets Curve', Journal of Economic Perspectives 16: 147-168.

De la Croix, D. and M. Doepke (2003), 'Inequality and growth: why differential fertility matters', American Economic Review 93: 1091-1113.

Egli, H. and T. M. Steger (2007), 'A dynamic model of the environmental Kuznet's curve', Environmental and Resource Economics 36: 15-34.

Grimaud, A. and L. Rouge (2003), 'Non-renewable resources and growth with vertical innovations: optimum, equilibrium and economic policy', Journal of Environmental Economics and Management 45: 433-453.

Grossman, G. M. and E. Helpman (1991), Innovation and Growth in the Global Economy, Cambridge, MA: The MIT Press.

Groth, C. (2007), 'A new growth perspective on non-renewable resources', in L. Bretschger and S. Smulders (eds), Sustainable Resource Use and Economic Dynamics, Dordrecht: Springer, pp. 127-163.

Groth, C. and P. Schou (2002), 'Can non-renewable resources alleviate the knife-edge character of endogenous growth?', Oxford Economic Papers 54: 386-411.

Hartwick, J. M. (1977), 'Intergenerational equity and the investing of rents from exhaustible resources', American Economic Review 67: 972-974.

Hayashi, F. (1982), 'Tobin's marginal q and average q: a neoclassical interpretation', Econometrica 50: 213-224.

Hotelling, H. (1931), 'The economics of exhaustible resources', The Journal of Political Economy 39: 137-175.

Jones, C. I. (1995), 'R\&D based models of economic growth', Journal of Political Economy 103: 759-784.

Kemfert, C. (1998), 'Estimated substitution elasticities of a nested CES production function for Germany', Energy Economics 20: S249-S264.

Landon, J. (1990), Incentive Regulation in the Electric Utility Industry, San Francisco, CA: National Economic Research Associates.

Lieb, C. M. (2004), 'The Environmental Kuznets Curve and flow versus stock pollution: the neglect of future damages', Environmental and Resource Economics 29: 483-506.

López, R., G. Anriquez, and S. Gulati (2007), 'Structural change and sustainable development', Journal of Environmental Economics and Management 53: 307322.

Mankiw, N. G., D. Romer, and D. N. Weil (1992), 'A contribution to the empirics of economic growth', Quarterly Journal of Economics 107: 407-437.

Mehlum, H., K. Moene, and R. Torvik (2006), 'Institutions and the resource curse', The Economic Journal 116: 1-20. 
Nordhaus, W. D. (1992), 'Lethal model 2: the limits to growth revisited', Brookings Papers on Economic Activity 2: 1-59.

Pittel, K. (2002), Sustainability and Endogenous Growth, Cheltenham: Edward Elgar.

Rivera-Batiz, L. A. and P. M. Romer (1991), 'International trade with endogenous technological change', European Economic Review 35: 971-1001.

Romer, P. M. (1990), 'Endogenous technological change', Journal of Political Economy 98: S71-S102.

Scholz, C. and G. Ziemes (1999), 'Exhaustible resources, monopolistic competition, and endogenous growth', Environmental and Resource Economics 13: 169-185.

Smulders, J. A. (2000), 'Economic growth and environmental quality', in H. Folmer and H. L. Gabel (eds), Principles of Environmental and Resource Economics, Cheltenham: Edward Elgar, pp. 602-664.

Smulders, J. A., L. Bretschger, and H. Egli (2005), 'Economic growth and the diffusion of clean technologies: explaining Environmental Kuznets Curves', Economics Working Paper Series 05/42, ETH Zurich.

Solow, R. (1974), 'Intergenerational equity and exhaustible resources', Review of Economic Studies 41, Symposium on the Economics of Exhaustible Resources, 2946.

Steger, T. M. (2007), 'Flexibility, sectoral hysteresis, and downturns', Macroeconomic Dynamics 11: 128-148.

Stern, D. I. (2004), 'The rise and fall of the Environmental Kuznets Curve', World Development 32: 1419-1439.

Stiglitz, J. (1974), 'Growth with exhaustible natural resources: efficient and optimal growth paths', Review of Economic Studies 41, Symposium on the Economics of Exhaustible Resources, 123-137.

Tamura, R. (2000), 'Growth, fertility and human capital: a survey', Spanish Economic Review 2: 183-229.

Xepapadeas, A. (2005), 'Economic growth and the environment', in K.-G. Mäler and J. R. Vincent (eds), Handbook of Environmental Economics 3, Amsterdam: Elsevier, pp. 1219-1271. 